\title{
Molecular Docking Studies of Phytocompounds from Withania Sominifera Against IL6 and JAK3 Targets in Rheumatoid Arthritis
}

\section{Gagan vishal saini}

Delhi Technological University Department of Biotechnology

Navneeta Bharadvaja ( $\square$ navneeta@dtu.ac.in )

Delhi Technological University Department of Biotechnology

\section{Research Article}

Keywords: Molecular, Rheumatoid, Withania somnifera

Posted Date: June 4th, 2021

DOl: https://doi.org/10.21203/rs.3.rs-573266/v1

License: (c) (1) This work is licensed under a Creative Commons Attribution 4.0 International License.

Read Full License 


\section{Abstract}

Rheumatoid arthritis is an auto immune disorder and inflammatory that decreases the life expectancy and it is characterized by persistent joint pain. This disease is not curable but can be maintained. People have been using a plant known as Withania somnifera or Indian Ginseng for its medicinal properties. The phytocompounds of this plant shows anti-inflammatory potentials against Rheumatoid Arthritis cytokine pathogenesis. In our study we are going to use IL6 and JAK3 protein as targets for docking and compounds of Withania somnifera as ligands.

\section{Introduction}

Rheumatoid arthritis (RA) is a life-long autoimmune illness characterized by chronic inflammation that causing joint pain and destroying cartilage and bone [1]. 1-3\% of the population is affected with this disorder all over the globe. Women over the age of 55 are 2-3 times more prone than men to Rheumatoid Arthritis. RA is symptomized by swelling, persisting pain, stiffness, Tenderness and flares or excaherbation especially in synovial joints (Knee, Shoulders, Elbows, Wrist, knuckles and feet) in the body. Synovial joints are present as a connection between the bones/cartilage that move against each other; normally 1-3 cells thick layer present at the site of synovial joint where synovial cavity is found. Synovial cavity is filled with a thick, dense, and viscous fluid known as Synovia or synovial fluid, that acts as a lubricant in bones friction or movement [7].

Synovial membrane or layer is hypertrophied in RA, and layer becomes (8-10 cells) thick joint space reduces because of that [2]. In this disorder, synovial area is heavily penetrated with own immune cells and inflammatory cells including lymphocytes ( $T$ and B cells) neutrophils, mast cells, eosinophils, and macrophages). New blood vessels are formed near the inflamed area. Because of this auto-immune mechanism, cartilage and bones are destroyed and eroded by the hypertrophied synovium and it leads deformity and dysfunction of bones and cartilage [8]. No permanent treatment is available, although many disease-modifying anti-rheumatic drugs (DMARDs), steroidal drugs, and non-steroidal antiinflammatory drugs are available in the market with severe to low side -effects and high cost [9].

India and its neighbouring countries (China,Bangladesh,Nepal and sri Lanka) have been using plants since ages for its surprising medicinal properties and therapeutic effects[3]. And "Withania somnifera" is one of the most used medicinal plants in India, Sri-Lanka and Bangladesh for its therapeutic potential. Withania somnifera is also known as the Indian Ginseng in local language and Ashwagandha in Hindi. It belongs to the family Solanaceae and found in hot and dried region areas. It is a shrub plant [10]. And has many medicinal properties including Anti-inflammatory, Anti-bacterial, Aphrodisiac, Anti-cancer, Adaptogenic, Anti-depression, and Anti-stress properties. Dried roots have been using for therapeutic use, studies show that leaves also have medicinal effects [4]. This plant has many phyto-compounds including Phenolics, Alkaloids, Steroidal and other compounds [5]. The disease "Rheumatoid Arthritis" is characterized by Inflammation and several cytokine pathways I/II on the molecular level [6]. So, we chose this Withania's 18 compounds for its anti-inflammatory potential as ligands. And Interleukin-6(IL6) and 
JAK3 as the target proteins involved in Rheumatoid Arthritis Pathogenesis. So, we used 18 ligands for molecular docking (This is a blind docking) against IL6 and JAK3 targets in Rheumatoid Arthritis.

\section{Materials And Methods Protein Preparation and Retrieval}

IL6[11] and JAK3[12] Protein's crystallographic structures were taken from RCSB Protein Data Bank (https://www.rcsb.org/) in pdb format. IL6 PDB ID is (1ALU) and JAK3 ID is (3LXK). IL6 is of 186 sequence length and JAK3 is of 327 sequence length. Both of the protein were edited suitably by using Molegro Molecular Viewer software by removing ligands and water molecules. For visualization, we used chimera software.

\section{Ligand Preparation}

Compounds we had selected as ligands were retrieved from (https://pubchem.ncbi.nlm.nih.gov/) by using their pubchem ID. And then we used Open Babel software to convert ligands from sdf format to mol2 format because the online docking software that we were using only accept in pdb or mol2 format. Compounds names and their pubchem ID are given in Table.1.

Table.1. 18 Withania somnifera compounds with their PubChem ID 


\begin{tabular}{|c|c|c|}
\hline Sr. no. & $\begin{array}{l}\text { Withania somnifera } \\
\text { Compounds }\end{array}$ & PubChem ID \\
\hline 1. & Tannic Acid & 161297 \\
\hline 2. & Rutin & 5280805 \\
\hline 3. & Somniferine & 14106343 \\
\hline 4. & Withasomniferol C & 101710597 \\
\hline 5. & Withaferin A & 265237 \\
\hline 6. & Chlorogenic Acid & 1794427 \\
\hline 7. & Quercetin & 528034 \\
\hline 8. & Withanolide A & 11294368 \\
\hline 9. & Kaempferol & 528034 \\
\hline 10. & Gallic Acid & 370 \\
\hline 11. & Choline & 305 \\
\hline 12. & Dulcitol & 11850 \\
\hline 13. & Withasomniferol B & 101710596 \\
\hline 14. & Withasomniferol A & 101710595 \\
\hline 15. & Cuscohygrine & 120154 \\
\hline 16. & Anaferine & 443143 \\
\hline 17. & Anahygrine & 12306778 \\
\hline 18. & Isopelletierine & 92987 \\
\hline
\end{tabular}

\section{Molecular Docking}

To perform the docking between target of Rheumatoid Arthritis and ligands of Withania somnifera we used SwissDock[13] online system. We uploaded the IL6 as a target in pdb format with Withania somnifera[14] 18 compounds one by one as ligand in mol2 format. And then ran the program and waited for results. Then after completing the docking of target IL 6 with all the 18 compounds, we again ran the program for 18 Withania somnifera ligands with JAK3 target this time. And as a result, we got 36 TargetLigand complexes. 


\section{Visualization}

After getting the SwissDock 36 results, we downloaded the target-ligand docked complex in the chimerax format. Then we studied all the 36 complexes via Chimera[15] software. After that We collected all the data including the number of hydrogen bonds formed between the target and a ligand, Intra residue $\mathrm{H}$ bonds distance, Estimated Delta $\mathrm{G}$ in $\mathrm{Kcal} / \mathrm{mol}$.

\section{Results And Discussions}

The 3D crystallographic structures of IL6 and JAK3 proteins were selected as target protein for docking with 18 phyto-compounds of Withania somnifera via SwissDock tool. The docking results showed the affinity between target and ligand. On the basis of binding energy obtained from 36 complexes, the highest affinity is shown by Interleukin 6-Tannic Acid complex and JAK3-Tannic Acid complex having a binding energy of -9.166905 and -12.074078 respectively. The results were visualized via Chimera software. The no. of hydrogen bonds present in interleukin 6-Tannic Acid complex are two and JAK3Tannic Acid complex are three in number. The binding pockets of IL6 where tannic acid bound are ASN 61 and ASP 140 at a distance of $2.005 \AA$ and $2.397 \AA$ between the complex respectively. The binding pockets of JAK3 where tannic acid bound are ASN 832, LYS 830, and ILE 991 at a distance of $2.448 \AA$, $2.373 \AA$, and $1.930 \AA$ between the complex respectively. Besides this, Rutin[16], Somniferine, and Withasomniferol $C$ also showed high binding energy in range of -8.7 to -7.7 with Interleukin- 6 target. Compounds Chlorogenic Acid, Quercetin, and Kaempferol also showed high binding energy in range of -8.1 to -7.8 with JAK3 target. More than 20 different poses were obtained for every complex structure out of which top energy level complex is selected due to high binding affinity along with more hydrogen bonds. The binding energy along with no of hydrogen bonds, binding pockets and Intra-residue $\mathrm{H}$-bonds Distance is shown in Table. 2 and Table. 3 of medicinal compound complexes with target Interleukin- 6 and JAK3.

Table.2. Details of binding energy and H bonds of target IL6 with 18 different compounds with Withania somnifera 


\begin{tabular}{|c|c|c|c|c|}
\hline $\begin{array}{l}\text { Sr. } \\
\text { no. }\end{array}$ & $\begin{array}{l}\text { Complex } \\
\text { (Target-Ligand) }\end{array}$ & $\begin{array}{l}\text { Estimated } \\
\Delta G \\
(\mathrm{kcal} / \mathrm{mol})\end{array}$ & $\begin{array}{l}\text { No of } \mathrm{H} \\
\text { bonds }\end{array}$ & $\begin{array}{l}\text { Intra-residue H-bonds } \\
\text { Distance }\end{array}$ \\
\hline 1. & Interleukin 6-Tannic Acid & -9.166905 & 2 & $2.005 \AA / 2.397 \AA$ \\
\hline 2. & Interleukin 6-Rutin & -8.7580595 & 1 & $2.559 \AA$ \\
\hline 3. & Interleukin 6-Somniferine & -7.834656 & 1 & $2.496 \AA$ \\
\hline 4. & $\begin{array}{l}\text { Interleukin 6- } \\
\text { Withasomniferol C }\end{array}$ & -7.775645 & 1 & $2.176 \AA$ \\
\hline 5. & Interleukin 6-Withaferin A & -7.574546 & 1 & $2.492 \AA$ \\
\hline 6. & $\begin{array}{l}\text { Interleukin 6-Chlorogenic } \\
\text { Acid }\end{array}$ & -7.3979516 & 1 & $2.271 \AA$ \\
\hline 7. & Interleukin 6-Quercetin & -7.35233 & 3 & $2.426 \AA 2 / 607 \AA$ \\
\hline 8. & Interleukin 6-Withanolide A & -7.11187177 & 1 & $2.39 \AA$ \\
\hline 9. & Interleukin 6-Kaempferol & -7.0464 & 2 & $2.460 \AA$ \\
\hline 10. & Interleukin 6-Gallic Acid & -6.9476986 & 2 & $2.347 \AA$ \\
\hline 11. & Interleukin 6-Choline & -6.9455814 & 1 & $2.269 \AA$ \\
\hline 12. & Interleukin 6-Dolcitol & -6.887075 & 2 & $2.435 \AA / 2.498 \AA$ \\
\hline 13. & $\begin{array}{l}\text { Interleukin 6- } \\
\text { Withasomniferol B }\end{array}$ & -6.7357774 & 1 & $2.492 \AA$ \\
\hline 14. & $\begin{array}{l}\text { Interleukin 6- } \\
\text { Withasomniferol A }\end{array}$ & -6.5323944 & 1 & $2.366 \AA$ \\
\hline 15. & Interleukin 6-Cuscohygrine & -6.51368 & 1 & $2.006 \AA$ \\
\hline 16. & Interleukin 6-Anaferine & -6.438672 & 1 & $2.075 \AA$ \\
\hline 17. & Interleukin 6-Anahygrine & -6.3276896 & 1 & $2.240 \AA$ \\
\hline 18. & Interleukin 6-Isopelletierine & -5.85198 & 2 & $2.432 \AA$ \\
\hline
\end{tabular}

Table.3. Details of binding energy and $\mathrm{H}$ bonds of target JAK3 with 18 different compounds with Withania somnifera. 


\begin{tabular}{|c|c|c|c|c|}
\hline $\begin{array}{l}\text { Sr. } \\
\text { no. }\end{array}$ & $\begin{array}{l}\text { Complex } \\
\text { (Target-Ligand) }\end{array}$ & $\begin{array}{l}\text { Estimated } \\
\Delta G \\
\text { (kcal/mol) }\end{array}$ & $\begin{array}{l}\text { No of } \mathrm{H} \\
\text { bonds }\end{array}$ & $\begin{array}{l}\text { Intra-residue H-bonds } \\
\text { Distance }\end{array}$ \\
\hline 1. & JAK3-Tannic Acid & -12.074078 & 3 & $2.448 \AA / 2.373 \AA / 1.930 \AA$ \\
\hline 2. & JAK3-Chlorogenic Acid & -8.157185 & 2 & $2.218 \AA ̊ / 2.059 \AA$ \\
\hline 3. & JAK3-Quercetin & -7.9316998 & 1 & $2.513 \AA$ \\
\hline 4. & JAK3-Kaempferol & -7.8692446 & 1 & $2.513 \AA$ \\
\hline 5. & JAK3-Somniferine & -7.738031 & 1 & $3.102 \AA$ \\
\hline 6. & $\begin{array}{l}\text { JAK3-Withasomniferol } \\
\text { B }\end{array}$ & -7.577868 & 1 & $2.177 \AA$ \\
\hline 7. & JAK3-Rutin & -7.522298 & 2 & $2.602 \AA / 2.166 \AA 33 c$ \\
\hline 8. & $\begin{array}{l}\text { JAK3-Withasomniferol } \\
\text { C }\end{array}$ & -7.517595 & 1 & $2.293 \AA$ \\
\hline 9. & JAK3-Anahygrine & -7.1745462 & 1 & $3.103 \AA$ \\
\hline 10. & $\begin{array}{l}\text { JAK3-Withasomniferol } \\
\text { A }\end{array}$ & -7.158677 & 1 & $2.529 \AA$ \\
\hline 11. & JAK3-Cuscohygrine & -7.1364365 & 1 & $3.075 \AA$ \\
\hline 12. & JAK3-Gallic Acid & -6.8791966 & 1 & $2.391 \AA$ \\
\hline 13. & JAK3-Withanolide A & -6.8321 & 2 & $2.369 \AA ̊ 丿 2.513 \AA$ \\
\hline 14. & JAK3-Dolcitol & -6.8012233 & 1 & $2.480 \AA$ \\
\hline 15. & JAK3-Anaferine & -6.67199447 & 1 & $2.352 \AA$ \\
\hline 16. & JAK3-Isopelletierine & -6.5186887 & 1 & $2.437 \AA$ \\
\hline 17. & JAK3-Withaferin A & -6.445368 & 2 & $2.010 \AA 2.396 \AA$ \\
\hline 18. & JAK3-Choline & -5.414158 & 1 & $2.330 \AA$ \\
\hline
\end{tabular}

The docked figures of the complexes of targets IL6 and JAK3 with 18 different compounds of Withania somnifera were obtained by a Chimera software. Figure- shows 


\section{Conclusions}

Using insilico method we have identified anti-rheumatoid arthritis inhibitors to stop the arthritis disorder. These inhibitors were obtained from Withania somnifera. The outcome of the study elucidates that Tannic Acid with IL6 and JAK3 targets showed highest binding energy and hence reveals a good potential as an anti-arthritic activity. Phytocompound Tannic acid possess immense potential as an effective lead compound.

\section{Declarations}

\section{Conflict of interest}

The authors declare that there is no any conflict of interest.

\section{Acknowledgement}

I want to thanks Dr. Navneeta Bharadvaja for her continuous support for proof reading.

\section{References}

1. Lee JE, Kim IJ, Cho MS, Lee J (2017 Jul) A Case of Rheumatoid Vasculitis Involving Hepatic Artery in Early Rheumatoid Arthritis. J Korean Med Sci 32(7):1207-1210

2. Mclnnes IB, Schett G (2011 Dec) The pathogenesis of rheumatoid arthritis. N Engl J Med 365(23):2205-2219

3. Alamanos Y, Voulgari PV, Drosos AA (2006 Dec) Incidence and prevalence of rheumatoid arthritis, based on the 1987 American College of Rheumatology criteria: a systematic review. Semin Arthritis Rheum 36(3):182-188

4. Piyarulli D, Koolaee RM (2016) A 22-Year-Old Female With Joint Pain. In: Piyarulli D, Koolaee RM (eds) Medicine Morning Report: Beyond the Pearls. Elsevier, Philadelphia, pp 65-77

5. Combe B, Landewe R, Daien $\mathrm{Cl}$, Hua C, Aletaha D, Álvaro-Gracia JM et al (2017 Jun) 2016 update of the EULAR recommendations for the management of early arthritis. Ann Rheum Dis 76(6):948-959

6. Richards BL, Whittle SL, van der Heijde DM, Buchbinder R (2012 Sep) The efficacy and safety of antidepressants in inflammatory arthritis: a Cochrane systematic review. J Rheumatol Suppl 90(0):21-27

7. Tian $\mathrm{H}$, Cronstein BN (2007) Understanding the mechanisms of action of methotrexate: implications for the treatment of rheumatoid arthritis. Bull NYU Hosp Jt Dis 65(3):168-173 
8. Volin MV, Harlow LA, Woods JM, Campbell PL, Amin MA, Tokuhira M et al (1999 Sep) Treatment with sulfasalazine or sulfapyridine, but not 5-aminosalicyclic acid, inhibits basic fibroblast growth factorinduced endothelial cell chemotaxis. Arthritis Rheum 42(9):1927-1935

9. Kumar P, Banik S (2013 Aug) Pharmacotherapy options in rheumatoid arthritis. Clin Med Insights Arthritis Musculoskelet Disord 6:35-43

10. Shiel WC Jr (2017) Rheumatoid Arthritis. (accessed 2017 May 12). Available from: http://www.medicinenet.com/rheumatoid_arthritis/article.htm

\section{Figures}
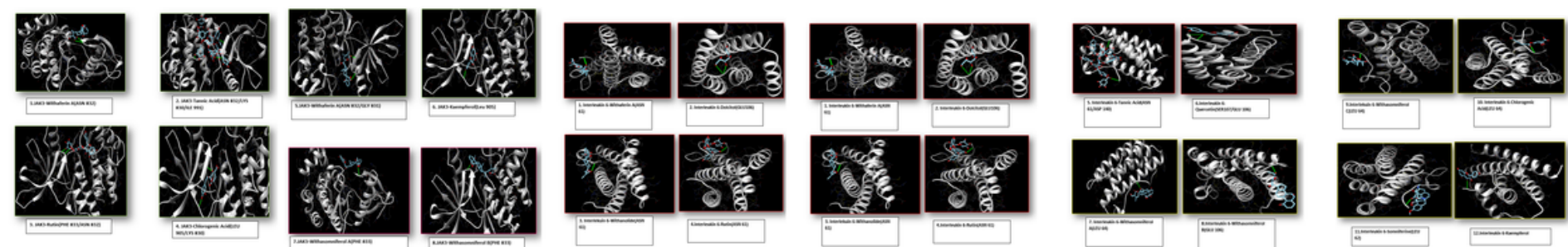

\section{Figure 1}

Complex of target ligand docking 